\title{
Trends in Joint Replacement Surgery in Patients with Rheumatoid Arthritis
}

\author{
Bradley L. Young, Shawna L. Watson, Jorge L. Perez, Gerald McGwin, Jasvinder A. Singh, \\ and Brent A. Ponce
}

ABSTRACT. Objective. This study analyzed trends in large total joint arthroplasties (TJA) and in the proportion of these procedures performed on patients with rheumatoid arthritis (RA).

Methods. The US Nationwide Inpatient Sample (2002-2012) was used to identify the incidences of total shoulder (TSA), elbow (TEA), knee (TKA), hip (THA), and ankle (TAA) arthroplasty and the proportion of these performed with coexisting RA.

Results. The prevalence of RA among patients with TJA increased 3.0\%. The prevalence of RA among cases of TEA and TSA decreased by $50 \%(\mathrm{p}<0.0001)$ and $18 \%(\mathrm{p}=0.0016)$, respectively; a $38.0 \%$ decrease occurred in the prevalence of RA among TAA $(\mathrm{p}=0.06)$; and nonsignificant increases were seen among THA and TKA. The average age difference between RA and non-RA patients undergoing TJA narrowed by 2 years $(\mathrm{p}<0.0001)$. There was a greater reduction in the proportion of TSA, TEA, and TAA groups among women with RA than men with RA. In the TSA and TEA groups, there was a reduction in the proportion of whites with RA, but not blacks. The proportion of privately insured TSA and TAA patients with RA decreased, while patients with RA undergoing TSA, TEA, or TAA who were receiving Medicaid (government medical insurance) remained relatively stable over time. Conclusion. The prevalence of RA has decreased among TSA and TEA patients. A nonsignificant decline occurred among TAA patients. The average age of TJA patients with RA is beginning to mirror those without RA. Sex ratios for TSA, TEA, and TAA patients are following a similar pattern. These results may be evidence of the success of modern RA treatment strategies. (First Release December 1 2017; J Rheumatol 2018;45:158-64; doi:10.3899/jrheum.170001)

Key Indexing Terms:

TOTAL JOINT ARTHROPLASTY SHOULDER ARTHROPLASTY ELBOW ARTHROPLASTY ANKLE ARTHROPLASTY DISEASE-MODIFYING ANTIRHEUMATIC DRUGS

Rheumatoid arthritis (RA) affects 1.3 million people in the United States $^{1}$. RA can lead to joint deformity and loss of function. About $25 \%$ of patients with RA undergo total joint arthroplasty (TJA) to relieve intractable pain and improve function $^{2}$.

Disease-modifying antirheumatic drugs (DMARD) can effectively retard joint damage in RA, ultimately delaying, and in some cases even preventing, the need for arthroplasty ${ }^{3}$. RA therapy has been revolutionized in the last 2 decades by the introduction and use of biological DMARD (bDMARD), which specifically target tumor necrosis factor or other pro-

From the University of Alabama at Birmingham (UAB) divisions of Orthopaedic Surgery, and Clinical Immunology and Rheumatology, and the Department of Epidemiology, Birmingham, Alabama; and the Carolinas Medical Center Department of Orthopaedic Surgery, Charlotte, North Carolina, USA.

B.L. Young, MD, Resident, Carolinas Medical Center Department of Orthopaedic Surgery; S.L. Watson, BA, Research Fellow, UAB Division of Orthopaedic Surgery; J.L. Perez, MD, Research Fellow, UAB Division of Orthopaedic Surgery; G. McGwin, MS, PhD, Professor and Vice Chairman, UAB Department of Epidemiology; J.A. Singh, MBBS, MPH, Professor, UAB Division of Clinical Immunology and Rheumatology; B.A. Ponce, MD, Associate Professor, UAB Division of Orthopaedic Surgery. Address correspondence to Dr. B.A. Ponce, 1313 13th St. South, Birmingham, Alabama 35205-5327,USA.E-mail: bponce@uabmc.edu Accepted for publication September 12, 2017. inflammatory cytokines involved in chronic synovitis and erosion of bony surfaces $3,4,5$. Compared to traditional DMARD, bDMARD usually require less time to take effect, have comparable efficacy, and may have fewer toxicities ${ }^{3,6,7}$; however, they are much more expensive than traditional DMARD, in general.

Without early diagnosis and prompt treatment, RA leads to severe joint morbidity, occupational disability, early retirement, and severe deficits in activities of daily living $8,9,10$. The percentage of patients with RA who eventually need at least 1 primary TJA has been reported as high as $31 \%^{11}$. Because TJA is often a definitive treatment option for severe RA, the severity of the national RA burden can be postulated by following surgical trends in the US population $^{12}$. Previous studies have analyzed the incidence of TJA in RA in various ways, including risk factors, time from diagnosis, and temporal trends from older time periods ${ }^{12,13,14}$. Our study's purpose was to take a different epidemiological approach and assess the temporal trends in the prevalence of RA in US patients undergoing TJA of the shoulder, elbow, hip, knee, and ankle. We hypothesized that the prevalence of RA has declined among those undergoing large TJA from 2002 to 2012.

Personal non-commercial use only. The Journal of Rheumatology Copyright @ 2018 . All rights reserved. 


\section{MATERIALS AND METHODS}

Our study was exempt from institutional review board approval because all patient data was de-identified and publicly available prior to study initiation.

The data for our study were obtained from the US National (formerly Nationwide) Inpatient Sample (NIS), a database maintained by the Agency for Healthcare Research and Quality. The NIS is the largest all-payer inpatient database in the United States and contains a $20 \%$ stratified sample of over 1000 hospitals participating in the Healthcare Cost and Utilization Project (HCUP) across the nation ${ }^{15}$. It should be noted that there were major changes in the NIS sampling mechanism in 2012; the sample now has a $20 \%$ stratification of inpatient stays in all participating HCUP hospitals.

Using the International Classification of Diseases-9-Clinical Modification (ICD-9-CM) procedural codes, the annual numbers of total shoulder (TSA), elbow (TEA), hip (THA), knee (TKA), and ankle (TAA) arthroplasties were calculated. Separately, the numbers of ankle fusion (AF), triple ankle arthrodesis (AA), shoulder hemiarthroplasty (HA), and reverse total shoulder arthroplasty (RTSA) were also calculated, because AF or AA and HA or RTSA procedures might be considered alternative procedures to TAA and TSA, respectively. Other than the TJA cohort, which is composed of TSA, TEA, THA, TKA, and TAA cohorts, all references to specific procedures throughout this manuscript concern only those procedures (i.e., TSA, HA, and RTSA cohorts are separate entities in every analysis). Of note, coding for RTSA began in October of 2010. The following procedural ICD-9 codes were used: 81.80 (TSA), 81.84 (TEA), 81.51 (THA), 81.54 (TKA), 81.56 (TAA), 81.11 (AF), 81.12 (AA), 81.81 (HA), and 81.88 (RTSA). These procedural groupings were then split into 2 groups: (1) patients with a primary or secondary diagnosis of RA, and (2) patients without this diagnosis. RA was identified using the ICD-9 code $714.0^{16}$.

The incidence of each type of arthroplasty was calculated using corresponding yearly US population estimates as the denominator. Poisson regression was used to evaluate whether the incidence of each type of arthroplasty changed over time. Estimates for overall time trends were obtained by comparing the final year of analysis (2012) to the first year of analysis (2002). To compare sample demographics between the first 2 years (2002-2003) and last 2 years (2011-2012) of the study period, the $t$ test and chi-square test were used to compare continuous and categorical variables, respectively. Statistics were performed using SAS version 8 for Macintosh. Statistical significance was determined as $\mathrm{p}<0.05$.

\section{RESULTS}

Arthroplasty trends in the general population. From 2002 to 2012, the incidence of TSA, TEA, THA, TKA, and TAA in the US population increased (Table 1). The incidence of TSA increased by $171 \%$ (9797 in 2002 to 29,750 in 2012) and TAA increased by $159 \%$ (1171 to 3405 ), which greatly exceeded the increase seen in the incidence of TKA $(60 \%$; $338,819$ to 610,409$)$, THA $(37 \% ; 194,355$ to 299,590$)$, and TEA (21\%; 1656 to 2245$)$. Over the study period, patients were most likely to undergo arthroplasty of the knee $(65.3 \%)$ or hip $(31.4 \%)$, followed by shoulder $(2.8 \%)$, elbow $(0.3 \%)$, and ankle $(0.2 \%)$.

$R A$ trends in arthroplasty patients. The prevalence of RA in patients undergoing TJA increased from 3.3\% to 3.4\% from 2002 to 2012 (Table 2). Stratified by specific anatomic location, this prevalence decreased for TSA $(5.0 \%$ to $4.1 \%$, $\mathrm{p}=0.0016)$ and TEA ( $24.0 \%$ to $12.0 \%, \mathrm{p}<0.0001$; Figure $1)$. The prevalence of RA in TAA declined almost to a significant level $(12.1 \%$ to $7.5 \%, p=0.059)$. The prevalence of RA in patients undergoing TKA and THA increased minimally (3.3\% to $3.4 \%$ and $2.9 \%$ to $3.1 \%$, respectively). For alter- native procedures, the prevalence of RA decreased in RTSA and AA $(5.9 \%$ to $5.4 \%, \mathrm{p}=0.054$, and $11.6 \%$ to $8.5 \%$, $\mathrm{p}<0.0001$ ), while AF and shoulder HA remained relatively stable.

Demographic trends in patients with RA undergoing TJA. When comparing the first 2 years of the study period (2002-2003) to the last 2 years (2011-2012), the mean age difference between non-RA and RA patients who underwent TJA decreased from 3.02 to 1.02 years $(\mathrm{p}<0.0001$, Table $3 \mathrm{~A}$ ), with RA patients being younger than non-RA patients undergoing the same surgeries, except for TEA patients in 2002-2003 (Table 3B). Stratifying this comparison by age $(<45,45-65,65-84, \geq 85$ yrs $)$ demonstrated that the percentage of patients having surgery in the 2 younger age categories decreased over time, while the percentage of patients having surgery in the 2 older age categories increased ( $p<0.0001)$. Stratifying TJA by joint and patients with RA by age showed a decrease in the percentage of TSA, TEA, or TAA being performed on patients in 1 or both of the younger age categories $(\mathrm{p}<0.05)$. The percentage of TSA, TEA, or TAA being performed on patients with RA in one of the older age categories increased or remained relatively the same. Although not depicted in Table $3 \mathrm{~A}$ or $3 \mathrm{~B}$, our data also showed that the age of THA and TKA patients with RA increased over the study period $(63.46 \pm 29.23$ yrs to 64.49 \pm 26.92 yrs, $\mathrm{p}=0.0024 ; 64.10 \pm 25.66 \mathrm{yrs}$ to $64.75 \pm 22.70$ yrs, $\mathrm{p}=0.0013$, respectively).

The percentage of both men and women patients with RA who underwent TSA and TEA decreased $(p=0.0061$ and $\mathrm{p}<0.0001$, respectively, for men; $\mathrm{p}<0.0001$ for women). For TAA, the female percentage decreased $(\mathrm{p}<0.0001)$ while the male percentage remained stable. The female-to-male reduction ratios for TSA, TEA, and TAA were $2.40,2.24$, and 6.01 , respectively.

The percentage of white patients with RA who underwent TSA, TEA, and TAA decreased ( $<<0.0001)$. Similarly, the percentage of black patients undergoing TAA decreased $(\mathrm{p}=0.0016)$; however, the percentage of black patients with RA who underwent TEA increased $(\mathrm{p}=0.047)$ and remained relatively unchanged in TSA.

The percentage of RA patients with private insurance who underwent TSA and TAA decreased $(\mathrm{p}<0.0001)$, while the percentage of RA patients with private insurance undergoing TEA remained relatively unchanged. The percentage of RA patients on Medicaid (government medical insurance) who underwent TSA, TEA, and TAA remained relatively unchanged over the study period.

\section{DISCUSSION}

Our study demonstrates a decrease in the prevalence of RA among patients undergoing TSA, TEA, and TAA. We also confirm that the incidence of TJA in the US population increased over 50\% between 2002 and 2012, reflecting an increasing trend ${ }^{17}$. It is acknowledged that TJA trends can

Personal non-commercial use only. The Journal of Rheumatology Copyright (c) 2018. All rights reserved. 
Table 1. Trends in total joint arthroplasty (TJA) in the US population, 2002-2012. Numbers in parentheses note incidence of procedures per 100,000 people as determined by US Census estimates (except in Total row).

\begin{tabular}{|c|c|c|c|c|c|c|}
\hline Year & All TJA & Shoulder & Elbow & Hip & Knee & Ankle \\
\hline 2002 & $545,801(190)$ & $9797(3.4)$ & $1656(0.58)$ & $194,355(68)$ & 338,819 (118) & $1171(0.41)$ \\
\hline 2003 & 578,192 (199) & $10,326(3.6)$ & $2238(0.77)$ & $195,619(67)$ & $369,000(127)$ & $1009(0.35)$ \\
\hline 2004 & $656,851(224)$ & $14,952(5.1)$ & $2362(0.81)$ & $219,188(75)$ & 418,919 (143) & $1429(0.49)$ \\
\hline 2005 & $732,054(248)$ & $16,285(5.5)$ & $2291(0.78)$ & $230,336(78)$ & $482,356(163)$ & $786(0.27)$ \\
\hline 2006 & $726,310(243)$ & $19,487(6.5)$ & $2538(0.85)$ & $221,639(74)$ & $481,804(161)$ & $842(0.28)$ \\
\hline 2007 & $802,826(267)$ & $22,589(7.5)$ & $2390(0.79)$ & $244,247(81)$ & $532,568(177)$ & $1032(0.34)$ \\
\hline 2008 & 886,535 (292) & $25,618(8.4)$ & $2165(0.71)$ & $265,768(87)$ & 591,493 (195) & $1490(0.49)$ \\
\hline 2009 & 906,733 (296) & $31,736(10.4)$ & $2566(0.84)$ & $274,090(89)$ & $596,781(195)$ & $1559(0.51)$ \\
\hline 2010 & $964,507(312)$ & $37,361(12.1)$ & $2609(0.84)$ & $290,959(94)$ & $631,082(204)$ & $2494(0.81)$ \\
\hline 2011 & 944,853 (296) & $28,128(8.8)$ & $2656(0.83)$ & 293,117 (92) & 617,823 (193) & $3128(0.98)$ \\
\hline 2012 & $945,399(294)$ & $29,750(9.2)$ & $2245(0.70)$ & $299,590(93)$ & 610,409 (189) & $3405(1.06)$ \\
\hline Total (\%) & $8,690,061(100)$ & $246,030(2.8)$ & $25,722(0.3)$ & $2,728,908(31.4)$ & $5,671,053(65.3)$ & $18,348(0.2)$ \\
\hline
\end{tabular}

Table 2. Prevalence (\%) of rheumatoid arthritis in all patients undergoing joint surgeries, 2002-2012.

\begin{tabular}{|c|c|c|c|c|c|c|c|c|c|c|}
\hline Year & All TJA & TSA & Reverse TSA & Shoulder HA & TEA & THA & TKA & TAA & $\mathrm{AF}$ & AA \\
\hline 2002 & 3.3 & 5.0 & & 4.9 & 24.0 & 2.9 & 3.3 & 12.1 & 6.7 & 11.6 \\
\hline 2003 & 3.2 & 5.4 & & 4.3 & 20.9 & 2.9 & 3.2 & 11.2 & 5.7 & 10.9 \\
\hline 2004 & 3.1 & 4.6 & & 5.0 & 18.5 & 2.7 & 3.2 & 10.8 & 5.4 & 10.5 \\
\hline 2005 & 3.1 & 5.4 & & 4.2 & 18.1 & 2.8 & 3.0 & 5.9 & 6.0 & 10.0 \\
\hline 2006 & 3.2 & 5.1 & & 4.1 & 19.2 & 3.0 & 3.2 & 7.9 & 4.8 & 9.9 \\
\hline 2007 & 3.1 & 5.5 & & 4.9 & 21.0 & 2.7 & 3.1 & 13.6 & 4.9 & 10.1 \\
\hline 2008 & 3.2 & 5.1 & & 2.5 & 15.5 & 2.8 & 3.2 & 10.6 & 6.2 & 7.7 \\
\hline 2009 & 3.1 & 4.9 & & 3.6 & 18.6 & 2.8 & 3.0 & 9.1 & 4.6 & 5.5 \\
\hline 2010 & 3.1 & 4.5 & 5.9 & 3.7 & 13.5 & 2.8 & 3.1 & 9.3 & 4.8 & 8.5 \\
\hline 2011 & 3.3 & 4.0 & 5.8 & 4.0 & 13.2 & 3.1 & 3.3 & 7.4 & 6.4 & 6.0 \\
\hline 2012 & 3.4 & 4.1 & 5.4 & 4.4 & 12.0 & 3.1 & 3.4 & 7.5 & 5.9 & 8.5 \\
\hline$\Delta 2002-2012$ & 0.1 & -0.9 & -0.5 & -0.6 & -12.0 & 0.2 & 0.1 & -4.6 & -0.7 & -3.1 \\
\hline $\mathrm{p}$ & & 0.0016 & 0.054 & 0.15 & $<0.0001$ & 0.13 & 0.38 & 0.059 & 0.57 & $<0.0001$ \\
\hline
\end{tabular}

42002-2012 represents the overall change in prevalence from 2002 to 2012 (not accounting for years in between). TJA: total joint arthroplasty; TSA: total shoulder arthroplasty; HA: hemiarthroplasty; TEA: total elbow arthroplasty; THA: total hip arthroplasty; TKA: total knee arthroplasty; TAA: total ankle arthroplasty; AF: ankle fusion; AA: ankle arthrodesis.

provide insight into the effect of modern RA treatment strategies, including early, aggressive therapy with a focus on achievement of low disease activity or remission (a treat-to-target approach) with an early use of methotrexate and the use of combinations of traditional and bDMARD, on the natural history of RA and its burden ${ }^{3,12}$. The trends demonstrated herein correspond to an era when DMARD were increasingly applied for RA therapy.

RA has been deemed a common indication for TSA, TEA, and TAA ${ }^{18,19,20,21}$. However, we found notable declines in the prevalence of RA among patients undergoing TSA $(-18 \%)$, TEA $(-50 \%)$, and TAA $(-38 \%)$ over the 11 -year study period (Table 1 and Table 2 ). We discuss these findings separately below. This is the most up-to-date report, to our knowledge, on the prevalence of RA in patients who underwent TJA. As far as we know, no previous studies have investigated past the year $2007^{13,14,19,22}$, highlighting the need for this updated analysis.

Historically, up to $80 \%$ of TEA have been indicated by
RA, and traumatic indications have remained stable over time $^{18}$. Herein is the first report, to our knowledge, of a significant reduction in RA prevalence among TEA. Not only was this reduction significant, but it was also the most profound among all TJA types. In light of this information, we concur with previous charges that TEA trends may serve as a useful gauge for overall TJA trends in the RA population ${ }^{18}$.

RA affects the shoulder in up to $90 \%$ of patients and is a likely indication for TSA ${ }^{20,21}$. A previous study, using data from a period prior to the application of modern RA therapy, found minor declines in TSA among patients with $\mathrm{RA}^{21}$. In contrast, our data demonstrated a significant reduction in the prevalence of RA among patients undergoing TSA between 2002 and 2012, which supports the theory that modern RA treatment models have affected TSA trends. Moreover, herein is the first assessment, to our knowledge, of RA trends in RTSA and HA, which have been advocated as treatment options for RA. Our data showed that the prevalence of RA

Personal non-commercial use only. The Journal of Rheumatology Copyright ()$_{2018}$. All rights reserved. 


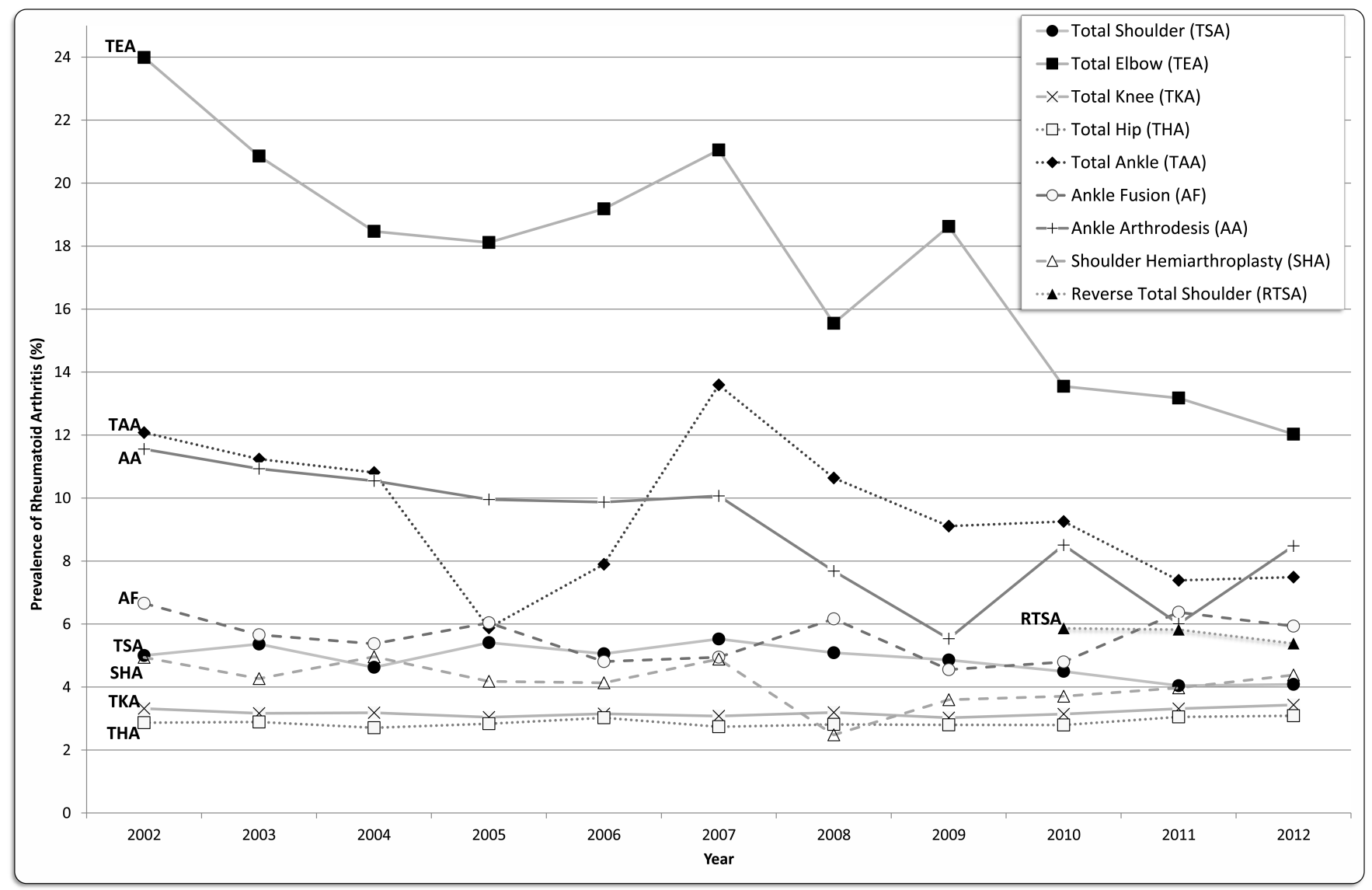

Figure 1. Prevalence of coexisting rheumatoid arthritis in patients undergoing joint surgeries from 2002 to 2012.

among these alternative procedures remained relatively stable, countering the argument that alternative operations may have affected our findings in our TSA cohort ${ }^{23}$.

Nearly $50 \%$ of patients with RA develop ankle disability ${ }^{24}$. A recent NIS study found that RA became a less common underlying diagnosis for TAA from 1998 to 2000 and 2009 to $2010^{25}$. Our findings demonstrated a continuance of this downward trend into 2012 and offered the first longitudinal observation of this trend. AA and AF have been established alternative therapies for endstage ankle damage secondary to RA. We offer the first comparison, to our knowledge, of national trends among patients with RA undergoing TAA, AA, or AF. The reduction in the prevalence of RA among patients undergoing AA may indicate a shift from ankle salvage toward ankle-sparing procedures for the treatment of RA.

A study by Jain, et $a l^{13}$ concluded that the growth rates of TJA among patients with RA had decreased from 1992 to 2005. However, this conclusion is not supported by the study's results because of methodological flaws. The authors did not calculate TJA rates in RA because they did not have population-based counts of patients with RA; rather, they calculated TJA rates in hospitalized patients with RA. Thus, the results of their study must be interpreted with caution because the authors did not account for the national prevalence of RA and changes that occurred over time. The findings of our current study provide a more accurate and updated interpretation of the relationship between RA and TJA in the United States.

We report that the age difference between non-RA and RA patients undergoing TJA narrowed by two-thirds $(66 \%$ reduction) between 2002 and 2003 and between 2011 and 2012 , owing to an increase in the age of patients with RA and a decrease in the age of non-RA patients over time (Table $3 \mathrm{~A}$ ). Age reduction in non-RA patients over time may be due to the increasing obesity in the population, leading to increased knee osteoarthritis (OA) and OA of the other joints, as well as an expanding age range for arthroplasty surgeries. This confirms a continuing trend recognized by Mertelsmann-Voss, et al, who concluded that the average age of patients with RA undergoing TJA was beginning to mirror that of patients undergoing TJA for noninflammatory conditions. Mertelsmann-Voss, et al attributed this to successful modern therapies that were shifting TJA indications in the RA population toward $\mathrm{OA}^{22}$. TKA and THA are the most prevalent arthroplasties performed in the general and RA populations $\mathrm{s}^{2,12,14,22}$. Patients with RA historically underwent TKA and THA earlier than patients with noninflammatory

\section{Personal non-commercial use only. The Journal of Rheumatology Copyright $\odot$ 2018 . All rights reserved}


Table 3A. Demographic comparisons among RA and non-RA patients in 2002-2003 and 2011-2012 for all TJA patients and those who had TSA.

\begin{tabular}{|c|c|c|c|c|c|c|c|c|c|c|}
\hline \multirow{4}{*}{$\begin{array}{l}\text { Procedure } \\
\text { Years } \\
\text { Cohort } \\
\text { Mean age, } \\
\text { yrs, } \pm \text { SD }\end{array}$} & \multicolumn{5}{|c|}{ All TJA } & \multicolumn{5}{|c|}{ TSA } \\
\hline & \multicolumn{2}{|c|}{$2002-2003$} & \multicolumn{2}{|c|}{ 2011-2012 } & \multirow[t]{2}{*}{$\mathrm{p}$} & \multicolumn{2}{|c|}{ 2002-2003 } & \multicolumn{2}{|c|}{ 2011-2012 } & \multirow[t]{2}{*}{$\mathrm{p}$} \\
\hline & Non-RA & RA & Non-RA & RA & & Non-RA & RA & Non-RA & RA & \\
\hline & $66.70 \pm 24.93$ & $63.68 \pm 27.06$ & $65.64 \pm 23.52$ & $\begin{array}{c}64.62 \pm \\
24.09\end{array}$ & $\begin{array}{l}<0.0001^{\mathrm{a}}, \\
<0.0001^{\mathrm{b}}\end{array}$ & $68.19 \pm 23.05$ & $62.05 \pm 28.48$ & $67.58 \pm 21.35$ & $65.12 \pm 23.32$ & $\begin{array}{l}0.0014^{\mathrm{a}} \\
0.0024^{\mathrm{b}}\end{array}$ \\
\hline \multicolumn{11}{|c|}{ Age groups (\%) } \\
\hline$<45 \mathrm{yrs}$ & 93.71 & 6.29 & 95.11 & 4.89 & $<0.0001$ & 78.77 & 21.23 & 89.19 & 10.81 & $<0.0001$ \\
\hline $45-64$ yrs & 96.27 & 3.73 & 96.51 & 3.49 & $<0.0001$ & 93.63 & 6.37 & 95.34 & 4.66 & $<0.0001$ \\
\hline $65-84$ yrs & 97.19 & 2.81 & 96.81 & 3.19 & $<0.0001$ & 95.90 & 4.10 & 96.40 & 3.60 & 0.0115 \\
\hline$\geq 85 \mathrm{yrs}$ & 98.14 & 1.86 & 97.55 & 2.45 & $<0.0001$ & 98.84 & 1.16 & 96.82 & 3.18 & 0.0040 \\
\hline \multicolumn{11}{|l|}{$\operatorname{Sex}(\%)$} \\
\hline Female & 95.96 & 4.04 & 95.73 & 4.27 & $<0.0001$ & 93.26 & 6.74 & 94.58 & 5.42 & $<0.0001$ \\
\hline Male & 98.11 & 1.89 & 98.05 & 1.95 & 0.0147 & 96.78 & 3.22 & 97.33 & 2.67 & 0.0061 \\
\hline \multicolumn{11}{|l|}{ Race (\%) } \\
\hline White & 96.99 & 3.01 & 96.90 & 3.10 & 0.0005 & 95.19 & 4.81 & 96.18 & 3.82 & $<0.0001$ \\
\hline Black & 95.03 & 4.97 & 94.84 & 5.16 & 0.0872 & 92.78 & 7.22 & 92.63 & 7.37 & 0.8998 \\
\hline \multicolumn{11}{|l|}{ Insurance (\%) } \\
\hline Private & 96.96 & 3.04 & 97.15 & 2.85 & $<0.0001$ & 93.38 & 6.62 & 96.02 & 3.98 & $<0.0001$ \\
\hline Medicaid & 94.20 & 5.80 & 95.44 & 4.56 & $<0.0001$ & 91.60 & 8.40 & 91.96 & 8.04 & 0.8188 \\
\hline
\end{tabular}

Table 3B. Demographic comparisons among RA and non-RA patients in 2002-2003 and 2011-2012 who had TEA and TAA.

\begin{tabular}{|c|c|c|c|c|c|c|c|c|c|c|}
\hline \multirow{4}{*}{$\begin{array}{l}\text { Procedure } \\
\text { Years } \\
\text { Cohort } \\
\text { Mean age, } \\
\text { yrs, } \pm \text { SD }\end{array}$} & \multicolumn{5}{|c|}{ TEA } & \multicolumn{5}{|c|}{ TAA } \\
\hline & \multicolumn{2}{|c|}{$2002-2003$} & \multicolumn{2}{|c|}{ 2011-2012 } & \multirow[t]{2}{*}{$\mathrm{p}$} & \multicolumn{2}{|c|}{$2002-2003$} & \multicolumn{2}{|c|}{ 2011-2012 } & \multirow[t]{2}{*}{$\mathrm{p}$} \\
\hline & Non-RA & RA & Non-RA & RA & & Non-RA & RA & Non-RA & RA & \\
\hline & $58.91 \pm 35.64$ & $60.41 \pm 28.89$ & $61.09 \pm 35.08$ & $\begin{array}{c}60.20 \pm \\
26.74\end{array}$ & $\begin{array}{l}0.0094^{\mathrm{a}} \\
0.8843^{\mathrm{b}}\end{array}$ & $59.14 \pm 28.66$ & $54.36 \pm 25.87$ & $63.19 \pm 23.68$ & $61.49 \pm 24.00$ & $\begin{array}{c}<0.0001^{\mathrm{a}}, \\
0.0003^{\mathrm{b}}\end{array}$ \\
\hline \multicolumn{11}{|c|}{ Age group (\%) } \\
\hline$<45 \mathrm{yrs}$ & 84.55 & 15.45 & 89.13 & 10.87 & 0.0088 & 83.80 & 16.20 & 87.33 & 12.67 & 0.2028 \\
\hline $45-64$ yrs & 75.27 & 24.73 & 85.01 & 14.99 & $<0.0001$ & 86.20 & 13.80 & 92.02 & 7.98 & $<0.0001$ \\
\hline $65-84$ yrs & 74.47 & 25.53 & 87.42 & 12.58 & $<0.0001$ & 92.95 & 7.05 & 93.51 & 6.49 & 0.5901 \\
\hline$\geq 85 \mathrm{yrs}$ & 96.95 & 3.05 & 98.46 & 1.54 & 0.2827 & 100.00 & 0.00 & 100.00 & 0.00 & - \\
\hline \multicolumn{11}{|l|}{$\operatorname{Sex}(\%)$} \\
\hline Female & 74.34 & 25.66 & 85.33 & 14.67 & $<0.0001$ & 83.17 & 16.83 & 89.30 & 10.70 & $<0.0001$ \\
\hline Male & 87.05 & 12.95 & 91.95 & 8.05 & $<0.0001$ & 95.29 & 4.71 & 96.31 & 3.69 & 0.1678 \\
\hline \multicolumn{11}{|l|}{ Race $(\%)$} \\
\hline White & 78.11 & 21.89 & 87.89 & 12.11 & $<0.0001$ & 89.12 & 10.88 & 93.09 & 6.91 & $<0.0001$ \\
\hline Black & 84.33 & 15.67 & 77.05 & 22.95 & 0.0469 & 65.72 & 34.28 & 83.38 & 16.62 & 0.0016 \\
\hline \multicolumn{11}{|l|}{ Insurance (\%) } \\
\hline Private & 83.13 & 16.87 & 84.94 & 15.06 & 0.1794 & 87.61 & 12.39 & 94.26 & 5.74 & $<0.0001$ \\
\hline Medicaid & 81.79 & 18.21 & 86.70 & 13.30 & 0.1207 & 84.75 & 15.25 & 87.90 & 7.91 & 0.5381 \\
\hline
\end{tabular}

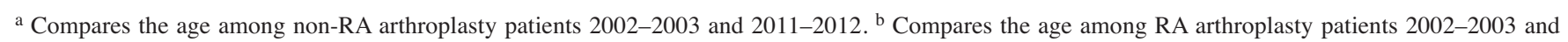
2011-2012. RA: rheumatoid arthritis; TJA: total joint arthroplasty; TSA: total shoulder arthroplasty; TEA: total elbow arthroplasty; TAA: total ankle arthroplasty.

indications ${ }^{22}$. Our study findings indicated that patients with RA are increasingly able to defer lower extremity arthroplasty to a later age. Additionally, our study is the first to identify reductions in this age discrepancy among patients with RA undergoing TSA and TAA. Age stratification indicated that patients with RA underwent TSA or TAA later in life, which suggests that current RA therapy is allowing patients to defer operative intervention of the shoulder and ankle until an older age. In contrast, we did not recognize age mirroring among the TEA cohort, which may be a product of increasing traumatic indications among younger patients ${ }^{18}$. Although we were unable to address many possible variables that could have led to the above findings, there is overarching opinion that these patterns correspond with improved medical treatment rather than a changing natural history of the disease ${ }^{19,22,26}$. However, one must continue to consider that these changes may be due to earlier diagnosis, changing environmental factors, or actual changes in the severity of $\mathrm{RA}^{27}$.

Our cross-sectional comparison of sex, ethnicity, and insurance status between 2 time periods (2002-2003 and 2011-2012) provides an update on the sex, race, and payer 
status disparities recognized among patients with RA who undergo TJA (Table 3A). Weyand, et al previously reported on the influence of sex on the phenotype of $\mathrm{RA}^{28}$. They found that joint erosion occurred more often and earlier in men; however, consequential joint destruction was greater in women. Further, their data showed that women with RA were twice as likely to undergo joint surgery than men. Although a sex discrepancy persisted in our study period, the reduction in the percentage of TSA, TEA, and TAA performed in females with RA was greater than that seen in males with RA, suggesting that the sex disparity is narrowing.

Previous studies have shown that RA severity, radiographic damage, and progression and functional status were worse in racial/ethnic minorities compared to whites, proving that minorities have worse disease and worse effect ${ }^{29,30,31,32}$. Our data showed that the percentage of TEA performed on white patients with RA is decreasing, but the percentage among blacks is increasing. A previous report found that TEA indicated by RA decreased among whites, while no significant change was seen among blacks ${ }^{33}$. Therefore, the novel evidence herein may indicate unaddressed or even worsening racial differences among patients with RA undergoing TEA. Among patients who undergo TSA, blacks are nearly twice as likely to have RA than whites ${ }^{33}$. We found that more TSA patients who had RA were black than white; further, the proportion of whites decreased while the black proportion remained unchanged, suggesting that this racial disparity gap may be widening. Possible explanations for the racial differences are treatment disparities based on race, or that blacks may prefer less aggressive RA therapy ${ }^{32}$. Regardless, the information presented in our study could be used by clinicians when educating patients of any race on the benefits of current RA therapy and expectations for future intervention. Also, disparities in care based on insurance status for individuals with RA have been well documented. Cifaldi, et al found that patients with Medicaid were less likely to see a rheumatologist or receive DMARD than patients with private insurance $(\mathrm{p}<0.01)^{34}$. Further investigations should be performed to help delineate the relationship between this disparity and our finding that TSA, TEA, and TAA rates remained unchanged among RA patients with Medicaid, while in the privately insured cohort, and TSA and TAA cohorts, there was a reduction in concomitant RA.

Our study has several limitations. First, when analyzing TJA rates, we used the entire general population as the denominator, instead of using the RA population. This methodology has been used in previous studies of TSA and TKA trends, but it leaves the chance that our data could have been affected by patients increasingly undergoing various TJA for other indications (i.e., OA) ${ }^{21,35}$. Because of the large amount of data and the complexity of NIS coding, clerical errors can occur during data entry; as a result of the absence of data on the validity of the ICD-9 code for RA in the NIS database, misclassification may have occurred, and the effect of this on study findings is unclear. We do not believe that any such inaccuracy would change significantly over time, therefore its effect on study of time trends is likely minimal. NIS data is also principally limited to inpatient hospital stays. Our study did not account for outpatient ankle arthrodeses and fusions. However, because most TJA are still performed as inpatient procedures, this is a minimal limitation for the practical purposes of our study. Unfortunately, the NIS does not specify indications for procedures, nor does it provide detailed diagnostic data such as radiologic erosion scores, which would have been useful in identifying the severity of RA-related joint disease ${ }^{36}$. Without such information, our interpretation assumes a high likelihood that patients with RA in our sample underwent TJA as a consequence of their rheumatic disease. Finally, we are not aware of any data that would allow us to accurately estimate the number of patients nationwide with RA through each year of the study period; this prevented us from calculating the temporal incidence of TJA in patients with RA. The US Centers for Disease Control and Prevention have perhaps the most recent and relevant published data on US prevalence of arthritis, but fail to distinguish between different etiologies (e.g., RA, OA, gout) ${ }^{37,38,39}$. Moreover, this NIS does not provide data on patient medications, which limited us from analyzing the effect of various treatment regimens on TJA rates. These limitations highlight areas for future improvement in the reporting of large, nationally representative samples.

While the overall incidence of TJA increased in the US population from 2002 to 2012, the prevalence of RA in patients undergoing TSA, TEA, and TAA decreased. The ages at time of surgery and sex ratios are beginning to mirror those of patients without RA across several specific arthroplasty types, but several racial disparities persist. These changes are likely related to the adoption of biological DMARD therapy or modern RA treatment models. This report provides information for surgeons and rheumatologists to help educate their patients with RA on the prognosis of their disease and the potential for operative intervention. Policy makers, hospitals, and other healthcare administrators may also consider these findings when planning for future trends.

\section{REFERENCES}

1. Helmick CG, Felson DT, Lawrence RC, Gabriel S, Hirsch R, Kwoh $\mathrm{CK}$, et al. Estimates of the prevalence of arthritis and other rheumatic conditions in the United States. Part I. Arthritis Rheum 2008;58:15-25.

2. Wolfe F, Zwillich SH. The long-term outcomes of rheumatoid arthritis: a 23-year prospective, longitudinal study of total joint replacement and its predictors in 1,600 patients with rheumatoid arthritis. Arthritis Rheum 1998;41:1072-82.

3. Doan QV, Chiou CF, Dubois RW. Review of eight pharmacoeconomic studies of the value of biologic DMARDs (adalimumab, etanercept, and infliximab) in the management of rheumatoid arthritis. J Manag Care Pharm 2006;12:555-69.

4. Scott DL, Pugner K, Kaarela K, Doyle DV, Woolf A, Holmes J, et

Personal non-commercial use only. The Journal of Rheumatology Copyright (C) 2018. All rights reserved. 
al. The links between joint damage and disability in rheumatoid arthritis. Rheumatology 2000;39:122-32.

5. Bresnihan B. Pathogenesis of joint damage in rheumatoid arthritis. J Rheumatol 1999;26:717-9.

6. Curtis JR, Singh JA. Use of biologics in rheumatoid arthritis: current and emerging paradigms of care. Clin Ther 2011; 33:679-707.

7. Quan LD, Thiele GM, Tian J, Wang D. The development of novel therapies for rheumatoid arthritis. Expert Opin Ther Pat 2008;18:723-38

8. Pincus T, Callahan LF, Sale WG, Brooks AL, Payne LE, Vaughn WK. Severe functional declines, work disability, and increased mortality in seventy-five rheumatoid arthritis patients studied over nine years. Arthritis Rheum 1984;27:864-72.

9. Reisine ST, Grady KE, Goodenow C, Fifield J. Work disability among women with rheumatoid arthritis. The relative importance of disease, social, work, and family factors. Arthritis Rheum 1989;32:538-43.

10. Wolfe F, Hawley DJ. The longterm outcomes of rheumatoid arthritis: Work disability: a prospective 18 year study of 823 patients. J Rheumatol 1998;25:2108-17.

11. Massardo L, Gabriel SE, Crowson CS, O'Fallon WM, Matteson EL. A population based assessment of the use of orthopedic surgery in patients with rheumatoid arthritis. J Rheumatol 2002;29:52-6.

12. Kapetanovic MC, Lindqvist E, Saxne T, Eberhardt K. Orthopaedic surgery in patients with rheumatoid arthritis over 20 years: prevalence and predictive factors of large joint replacement. Ann Rheum Dis 2008;67:1412-6.

13. Jain A, Stein BE, Skolasky RL, Jones LC, Hungerford MW. Total joint arthroplasty in patients with rheumatoid arthritis: a United States experience from 1992 through 2005. J Arthroplasty 2012;27:881-8

14. Waljee J, Zhong L, Baser O, Yuce H, Fox DA, Chung KC. The incidence of upper and lower extremity surgery for rheumatoid arthritis among Medicare beneficiaries. J Bone Joint Surg Am 2015;97:403-10

15. HCUP Databases. Healthcare Cost and Utilization Project (HCUP). February 2016. Agency for Healthcare Research and Quality, Rockville, MD. [Internet. Accessed October 31, 2017.] Available from: www.hcup-us.ahrq.gov/nisoverview.jsp

16. International Classification of Diseases, Ninth Revision, Clinical Modification (ICD-9-CM). National Center for Health Statistics, 2011. [Internet. Accessed October 31, 2017.] Available from: www.cdc.gov/nchs/icd/icd $9 \mathrm{~cm}$. htm

17. Yoshihara H, Yoneoka D. Trends in the incidence and in-hospital outcomes of elective major orthopaedic surgery in patients eighty years of age and older in the United States from 2000 to 2009. J Bone Joint Surg Am 2014;96:1185-91.

18. Jenkins PJ, Watts AC, Norwood T, Duckworth AD, Rymaszewski LA, McEachan JE. Total elbow replacement: outcome of 1,146 arthroplasties from the Scottish Arthroplasty Project. Acta Orthop 2013;84:119-23.

19. Louie GH, Ward MM. Changes in the rates of joint surgery among patients with rheumatoid arthritis in California, 1983-2007. Ann Rheum Dis 2010;69:868-71.

20. Chen AL, Joseph TN, Zuckerman JD. Rheumatoid arthritis of the shoulder. J Am Acad Orthop Surg 2003;11:12-24.

21. Jain NB, Higgins LD, Guller U, Pietrobon R, Katz JN. Trends in the epidemiology of total shoulder arthroplasty in the United States from 1990-2000. Arthritis Rheum 2006;55:591-7.

22. Mertelsmann-Voss C, Lyman S, Pan TJ, Goodman SM, Figgie MP, Mandl LA. US trends in rates of arthroplasty for inflammatory arthritis including rheumatoid arthritis, juvenile idiopathic arthritis, and spondyloarthritis. Arthritis Rheumatol 2014;66:1432-9.
23. Gee EC, Hanson EK, Saithna A. Reverse shoulder arthroplasty in rheumatoid arthritis: a systematic review. Open Orthop J 2015;9:237-45.

24. Pedersen E, Pinsker E, Younger AS, Penner MJ, Wing KJ, Dryden PJ, et al. Outcome of total ankle arthroplasty in patients with rheumatoid arthritis and noninflammatory arthritis. A multicenter cohort study comparing clinical outcome and safety. J Bone Joint Surg Am 2014;96:1768-75.

25. Singh JA, Ramachandran R. Time trends in total ankle arthroplasty in the USA: a study of the National Inpatient Sample. Clin Rheumatol 2016;35:239-45.

26. Finckh A, Choi HK, Wolfe F. Progression of radiographic joint damage in different eras: trends towards milder disease in rheumatoid arthritis are attributable to improved treatment. Ann Rheum Dis 2006;65:1192-7.

27. Walji S, Bykerk VP. Rheumatoid arthritis: is the disease becoming milder or is treatment improving? J Rheumatol 2004;31:1023-5.

28. Weyand CM, Schmidt D, Wagner U, Goronzy JJ. The influence of sex on the phenotype of rheumatoid arthritis. Arthritis Rheum 1998;41:817-22.

29. Greenberg JD, Spruill TM, Shan Y, Reed G, Kremer JM, Potter J, et al. Racial and ethnic disparities in disease activity in patients with rheumatoid arthritis. Am J Med 2013;126:1089-98.

30. Barton JL, Trupin L, Schillinger D, Gansky SA, Tonner C, Margaretten M, et al. Racial and ethnic disparities in disease activity and function among persons with rheumatoid arthritis from university-affiliated clinics. Arthritis Care Res 2011;63:1238-46.

31. Bridges SL Jr., Causey ZL, Burgos PI, Huynh BQ, Hughes LB, Danila MI, et al. Radiographic severity of rheumatoid arthritis in African Americans: results from a multicenter observational study. Arthritis Care Res 2010;62:624-31.

32. Constantinescu F, Goucher S, Weinstein A, Fraenkel L. Racial disparities in treatment preferences for rheumatoid arthritis. Med Care 2009;47:350-5.

33. Singh JA, Ramachandran R. Are there racial disparities in utilization and outcomes after total elbow arthroplasty? Rheumatol Int 2015;35:1479-87.

34. Cifaldi M, Renaud J, Ganguli A, Halpern MT. Disparities in care by insurance status for individuals with rheumatoid arthritis: analysis of the medical expenditure panel survey, 2006-2009. Curr Med Res Opin 2016;32:2029-37.

35. Jain NB, Higgins LD, Ozumba D, Guller U, Cronin M, Pietrobon R, et al. Trends in epidemiology of knee arthroplasty in the United States, 1990-2000. Arthritis Rheum 2005;52:3928-33.

36. Goekoop-Ruiterman YP, de Vries-Bouwstra JK, Allaart CF, van Zeben D, Kerstens PJ, Hazes JM, et al. Clinical and radiographic outcomes of four different treatment strategies in patients with early rheumatoid arthritis (the BeSt study): A randomized, controlled trial. Arthritis Rheum 2008;58 Suppl 2:S126-35.

37. Cheng YJ, Hootman JM, Murphy LB, Langmaid GA, Helmick CG; Centers for Disease Control and Prevention (CDC). Prevalence of doctor-diagnosed arthritis and arthritis-attributable activity limitation - United States, 2007-2009. MMWR Morb Mortal Wkly Rep 2010;59:1261-5.

38. Barbour KE, Helmick CG, Theis KA, Murphy LB, Hootman JM, Brady TJ, et al. Prevalence of doctor-diagnosed arthritis and arthritis-attributable activity limitation-United States, 2010-2012. MMWR Morb Mortal Wkly Rep 2013;62:869-73.

39. Hootman JM, Helmick CG, Barbour KE, Theis KA, Boring MA. Updated projected prevalence of self-reported doctor-diagnosed arthritis and arthritis-attributable activity limitation among US adults, 2015-2040. Arthritis Rheumatol 2016;68:1582-7. 